\title{
LA TORTURA: TODO ES CUERPO ${ }^{1}$
}

\author{
José Santos Herceg²
}

\section{Resumen/Abstract}

En este texto se intenta una aproximación al tema de la tortura desde la perspectiva del cuerpo. De hecho este es un elemento central de la tortura, al punto de que se podría decir que en ella todo es cuerpo. Es un arma para los torturadores, el saber acerca del cuerpo es una herramienta tecnológica que puede ser usada para torturar; es una suerte de traidor que hace vulnerables a las víctimas. El cuerpo de la víctima es lo dañado, aunque lo dañado se extiende también a su familia y al cuerpo social, a la comunidad de las víctimas.

Palabras clave: tortura, cuerpo, dictadura, víctima, torturador

\section{TORTURE: ALL IS BODY}

This paper attempts an approach to torture from he perspective of the body. In fact, this a central element of torture, to the point that in it all is body. It is a weapon for the torturers, the knowledge about the body is a technological tool that can be used in torture; it is a sort of traitor, that makes the victims vulnerable. The body of the victim is what is damaged by torture and the damage expands also to the family of the victims, to the social body, and to community.

Keywords: torture, body, dictatorship, victim, torturer

1 Este trabajo forma parte de la investigación titulada Campos prisioneros en Chile. Reconfiguración de los lugares y las subjetividades (FONDECYT No 1140200).

2 Chileno, Instituto de Estudios Avanzados, Universidad de Santiago. Email: jose. santos@usach.cl

Recibido el 10/07/2015

Aceptado el 18/11/2015 
La Dictadura Militar chilena fue, en gran medida, una ejercicio sobre los cuerpos: sobre los cuerpos de los chilenos, sobre el cuerpo de Chile como ha hecho ver Valentina Bulo (2013: 208). Sin pretensión alguna de exhaustividad, es posible distinguir al menos los siguientes órdenes de procedimientos implementados por la dictadura sobre los cuerpos: por una parte, acciones destinadas a ordenarlos, encauzarlos, determinarlos, en síntesis, disciplinamiento de los cuerpos; por otra, acciones destinadas a atraparlos, encerrarlos, amarrarlos, es decir, inmovilización de los cuerpos; en tercer lugar, acciones destinadas a esconderlos, ocultarlos, taparlos, negarlos, en una palabra, desaparición de los cuerpos; además se implementan acciones destinadas a denigrarlos, exponerlos, violentarlos, es decir, profanación de los cuerpos; en quinto lugar, se llevan a cabo acciones destinadas a herirlos, dañarlos, quebrarlos: ruptura de los cuerpos; finalmente, hubo acciones para mutilarlos, cercenarlos, invalidarlos, dicho más directamente, destrucción de los cuerpos.

Todos estos procedimientos están evidentemente vinculados con la tortura. Ella es, de hecho, una acción de profanación, ruptura, disciplinamiento, inmovilización y destrucción de los cuerpos. Si la dictadura fue, como se decía, un ejercicio sobre los cuerpos, y en dicho ejercicio la tortura participa permanente y transversalmente, entonces es posible sostener que la tortura fue un dispositivo fundamental para dicho régimen. La tortura no fue una acción más, no fue una herramienta o una estrategia entre otras, sino que estuvo definitiva y fundamentalmente vinculada con la dictadura chilena; fue un engranaje central que la define en su esencia. No es posible, de hecho, pensar profundamente en la dictadura chilena, sin referirse al fenómeno de la tortura. Cuando en 1989-90 Patricio Marchant señalaba que el deber del "intelectual negativo" era "iniciar el comentario de la catástrofe nacional" (Marchant, 2000: 222), ello implicaba, por lo tanto, iniciar el comentario de la tortura.

La tortura en general, pero muy especialmente la tortura en Chile, fue y es, no obstante, un fenómeno rodeado, sitiado, atravesado por silencios. Ello, por supuesto, no es una constatación sorprendente ni novedosa: el tema aparece incluso en el títulos de algunos de los textos más importantes que se han escrito sobe el tema. López y Otero constataban ya hace años que "Una de las tantas paradojas que rodea la existencia de la tortura es que, no obstante su recurrencia, de ella prácticamente no se habla" (1989:11). En el 
ámbito académico chileno este diagnóstico se corrobora, pues existen tan solo un puñado de trabajos sobre la tortura durante la dictadura. Habría que mencionar, sin duda, el recién citado escrito de López y Otero (1978), pero también los de Sánchez (1990), Tricot (1990), Reszcynski, Rojas, y Barceló (1991), Vásquez, Rojas, y Reszcynski, (1994), Westin (1994), la compilación de Soto (1999), el trabajo de Guerrero (1999), el de Vidal (2000), el texto editado por Verdugo (2004), y el libro de Moya (2005). En estos más de cuarenta años que han pasado desde el Golpe de Estado los trabajos de largo aliento sobre tortura no superan la docena, a lo que se agregan algunos artículos como los de Madariaga (1989), Fuentes y Correa (2010), los de Moulian, Garretón, Rojas, Lira y Loveman y otros, compilados por Patricia Verdugo (2004), el de Marrades (2005), el de Bulo (2013), junto a algunos más.

El silencio se explica en parte, sin duda, por la dificultad para hablar de la tortura. Referirse a ella es difícil, lo es por el miedo, lo es por la exposición que ello implica, lo es porque se quiere olvidar, porque no se quiere volver a ella. Se constata en el Informe Valech que descorrer el velo de la tortura, de la humillación, de la violación física y psicológica es algo muy difícil de hacer. No se trata, sin embargo, solo de una dificultad psicológica, social o política, pues hablar de la tortura es también difícil teóricamente. Ella representa para la reflexión un reto complicado de abordar en muchos sentidos diferentes. Sin ir más lejos, uno de los problemas más complejos es que ni siquiera esté muy claro lo que se entiende por tortura. Como muy bien ha dicho Maier, "Finding a definition of torture is a notoriously dificult task" (2011: 103). Sussman ya había señalado que "Torture has proved surprisingly difficult to define" (2005: 1).

En este texto se intentará una aproximación temática inicial: abordar la tortura solo desde la perspectiva del cuerpo. Esta aparente humildad del abordaje propuesto se revelará prontamente como un espejismo, pues el cuerpo colma el fenómeno de la tortura al punto de que se podría decir, como intentaré mostrar, que en ella todo es cuerpo. El cuerpo que es usado como arma en el caso de los torturadores, el saber del cuerpo que se vuelve una herramienta tecnológica útil y necesaria para torturar, el cuerpo que traiciona en tanto que hace vulnerables a las víctimas, el cuerpo de la víctima que es aquello dañado por la tortura y un daño que se extiende a la familia y al cuerpo social completo.

\section{Cuerpo como arma: el verdugo}

Pese a lo que podría constituir una primera intuición al respecto y en directa contradicción con lo que las víctimas piensan y sienten, a estas 
alturas parece relativamente claro que entre los torturadores no hay, al menos no habitualmente, "agresividad instintiva irremediable" (López y Otero, 1989:93), como tampoco hay locura ni insanidad mental, anomalías psicológicas o perversión natural. En la literatura parece estar relativamente claro que se trata de sujetos que en principio habría que calificar de normales. Irrumpe, entonces, aquella misma perplejidad de la que habla Hannah Arendt al referirse a Eichmann:

Me impresionó la manifiesta superficialidad del acusado, que hacía imposible vincular la incuestionable maldad de sus actos a ningún nivel más profundo de enraizamiento o motivación. Los actos fueron monstruosos, pero el responsable - al menos el responsable efectivo que estaba siendo juzgado- era totalmente corriente, del montón, ni demoníaco ni monstruoso (1984: 14).

Si hay algo en lo que parece haber unanimidad entre los autores es en el hecho de que nadie nace verdugo, sino que llega a serlo. La pregunta, más de una vez planteada es, entonces, “¿Cómo es posible que [alguien] lleguen a ejercer por oficio actividades 'inhumanas"? (CODEPU, 1985: 18) ¿Cómo es posible que alguien se vuelva un torturador? La respuesta, sin pretensión alguna de ser definitiva, no puede descartar la existencia de ciertas condiciones previas: una formación fuertemente ideologizada -incluso desde el núcleo familiar-, la existencia de fuertes prejuicios y, sin duda, la concurrencia de rasgos de la personalidad como son, en términos de López y Otero:

...tener creencias rígidas, ser intolerante hacia la debilidad (propia o ajena), ser altamente punitivo, receloso y exageradamente respetuoso de la autoridad; muy incomprensivo y, correlativamente, inclinado a la indignación moral; muy conformista y tradicionalista. Estos rasgos son relacionados con una debilidad del yo, con una inseguridad que busca compensarse en modelos inconmovibles de conducta (1989: 110).

Como sea, pese a la existencia de estas condiciones, lo más relevante, lo decisivo, es el hecho de recibir una determinada formación. Un verdugo no nace, sino que se hace o, como dice Hernán Valdés en su testimonio, "los torturadores no se improvisan, se educan" (1978: 144). La pregunta entonces se desplaza: ¿Cómo se construye un torturador? ¿Cómo se convierte a un sujeto normal en un verdugo? Aunque con ello se está lejos de agotar el tema, sin embargo, es relativamente claro que el cuerpo, la educación corporal, el trabajar con el cuerpo sin lugar a duda es central en esta formación (Cf.: CODEPU, 1985: 20-21). 
El cuerpo del futuro torturador es entrenado, en primer lugar, al nivel de las emociones. El asco, el horror, la repugnancia, por ejemplo, deben ser bloqueados para que no se interpongan en su tarea. Del mismo modo, emociones positivas como son el amor, la ternura, la solidaridad, la compasión, la protección, simplemente deben ser neutralizadas con el objetos de que pueda desempeñar su labor sin problemas (Cf.: CODEPU, 1985: 25). Al aprendiz de torturador se le enseña a sentir lo que debe sentir y a eliminar todo tipo de emociones que se interpongan en el cumplimiento de su deber. Para ello se utilizan "metodologías progresivas" con dos técnicas principalmente: "la desensibilización progresiva y el condicionamiento operante" (CODEPU, 1985: 25).

En el texto de la CODEPU se alude a una serie de acciones concretas destinadas a ello. En primer lugar, incorporar a los iniciados como observadores en las torturas, luego se avanza con una participación menor en algunos procedimientos y técnicas simples, participan posteriormente de forma directa en actos de "crueldad pura" y finalmente actúan en interrogatorios y eliminación de detenidos (Cf.:25-26). Además hay otras formas de inducción/ formación alternativas como son la obligación de realizar atrocidades con animales, ver películas con contenidos crueles para luego relatar detalles banales de las escenas, transformar al futuro torturador en víctima de torturas por parte de sus colegas o camaradas, hacer que la tortura no aparezca como tan brutal: aplicarla sin dejar huellas, siendo "sofisticado" y "científico", tender a una "tecnificación despersonalizada" del trabajo, mayor uso de técnicas psicológicas que físicas, etc.

El cuerpo debe ser entrenado, en segundo lugar, para lograr una respuesta inmediata, espontánea, directa. No hay lugar para la duda, para la reflexión. Ante una orden, el verdugo debe actuar decididamente. Para ello se construye un condicionamiento del tipo conductista. En el más original sentido en que fuera pensado por Pavlov: ante el estímulo de una orden directa el cuerpo del verdugo se mueve casi automáticamente sin dudar, como un máquina que ha sido programada para ello. "La obediencia absoluta se obtiene por un sistema muy simple de premio-castigo, en el que predomina el castigo naturalmente. Desde el momento en que el funcionario está siendo seleccionado -e involucrado- en actos de tortura y asesinato, la obediencia automática se refuerza además por el miedo a los castigos en caso de debilidad, hesitaciones o desobediencia" (CODEPU, 1985: 28).

El cuerpo debe ser entrenado, también, al nivel "técnico". Habrá que desarrollar destrezas en el uso de los instrumentos de tortura: picana, esposas, 
palos, látigos, etc. Aunque también se trabaja el propio cuerpo del torturador como instrumento directo de tortura. El futuro verdugo ha de saber golpear, amarrar, apretar... incluso violar. Para hacerlo se requiere de entrenamiento físico: el cuerpo habrá de ser fuerte, estar trabajado, templado para que responda como se desea. Templar el cuerpo pasa, por supuesto, por dominar el dolor; es por ello que el futuro torturador es sometido a la tortura como parte de su preparación. En no pocas oportunidades los sujetos que están siendo entrenados son vejados, golpeados, encerrados, incluso violados por sus colegas o camaradas. Esto ocurre especialmente en el caso de las llamadas "fuerzas especiales", pero en general se trata de un "entrenamiento" bastante habitual y, si extendemos a otros países lo que dice Pereyra para el caso Argentino, se trata de prácticas aún vigentes (2004).

Es así como el cuerpo del torturador se entrena, se forma, se modela como un arma, se afila como un cuchillo para ser certero y eficiente en su tarea. El torturador debe saber qué hacer y debe hacerlo con rapidez y seguridad. Sus movimientos deben ser nítidos, sus pasiones deben estar bajo control. Su entrenamiento, sin embargo, implica también la adquisición de un determinado saber: un saber del cuerpo.

\section{Saber del cuerpo: la tecnología}

Se ha dicho que el torturador es un "sujeto colectivo", que por torturador debe entenderse un equipo, un colectivo. La acción de torturar, por lo tanto, no puede considerarse simplemente como aquella que realiza un sujeto en solitario: poner electricidad, golpear, violar, etc. Como ha escrito acertadamente Egaña,

el torturador es una colectividad desde que el tormento es aplicado por un equipo: el carcelero que saca al detenido de su celda y lo conduce a la sala de torturas; el guardia que lo recibe con insultos y golpes, y lo ata a la parrilla; el oficial que lo interroga preguntando insistentemente el paradero de otro militante; el soldado que acciona la corriente eléctrica; el médico que examina un cuerpo exhausto para saber cuánto más resistirá, etc. Son equipos complejos, de alta especialización y cohesión interna, que trabajan por turnos y de forma rotativa" (2005:92). 
La tortura es una acción que tendríamos que calificar de compleja, pues está compuesta de una pluralidad de actos individuales pero interconectados, cada uno de los cuales es parte esencial de la tortura. Tortura el que da la orden, el que toma detenido, el que lleva a la sala, el que vigila fuera de la celda, el que golpea, el que pone la picana, el que da vuelta a la manivela, etc. La acción de torturar es, entonces, un entramado, un enjambre de actos que van desde el arresto, pasando por las vejaciones, las privaciones, los golpes, los interrogatorios, las flagelaciones, etc., hasta el silencio del que no denuncia.

No se crea, sin embargo, que este conglomerado de actos que conforman la tortura es caótico ni menos azaroso. La acción de torturar, así como cada acto que la constituye son el resultado de un saber: del saber torturar, en el sentido de saber causar dolor, saber destruir, saber provocar miedo, etc. La pregunta que se podría plantar, entonces, es qué tipo de saber es la tortura. Aristóteles hace al inicio de la Metafísica una serie de observaciones que permiten iluminar este asunto. El filósofo habla allí de una diferencia entre el saber que se tiene a partir de la experiencia de casos particulares, que podría llamarse "saber técnico", y el que se tiene en tanto que a partir de la experiencia se elabora un conocimiento más universal, que el autor llama "arte" y luego califica de "ciencia". La diferencia aquí es que "unos saben la causa, y los otros no. Pues los expertos saben el qué, pero no el porqué. Aquellos, en cambio, conocen el porqué y la causa" (981a: 27-29).

El saber de la tortura se desplaza justamente en estos dos niveles: hay expertos que saben torturar pues, por una parte, tienen experiencia y, por otra, han sido formados, enseñados por otros que conocen las causas y han desarrollado el saber teórico a partir de la experiencia. Están, entonces, los técnicos y los científicos de la tortura: los primeros actúan de acuerdo con un "saber cómo" aprendido, los segundos desarrollan un "saber por qué" que se enseña. Natalie Pérez habla con razón de una "economía de lo doloroso" que se encarna en la confección de una serie de técnicas. Hay una tecnología del dolor que se le enseña al torturador y que se aplica, como se dijo, directamente sobre el cuerpo de las víctimas. "La tortura (...) es una técnica que apunta, de manera calculada y reglamentada, a provocar la mayor cantidad de sufrimiento posible..." (2009: 103). Pérez anota que en el caso de la tortura existe un "catálogo extenso de técnicas" y que en la búsqueda por causar el mayor dolor posible, se desarrolla esta “...economía de lo doloroso" que “... pone a la ciencia y la técnica a operar al servicio de los mecanismos para ejercer suplicios. Anatomía y tecnología aportan el dónde y el cómo utilizar los aparatos para torturar" (2009: 108-9). 
Daniel Pereyra cuenta que "Fueron los militares franceses los que desarrollaron la doctrina de la guerra antisubversiva en Vietnam y en Argelia transmitiendo luego su experiencia a sus colegas de Estados Unidos y de América Latina" (2004: 83). La tecnología de la tortura es una parte central de las técnicas militares desarrolladas en este contexto. En 1960 en la llamada Escuela de la Américas (creada en 1946), “... los norteamericanos invitan a sus colegas franceses para que expliquen la doctrina de la guerra sucia” (85). Según señala Pereyra, los franceses enviaron especialistas en interrogar y torturar, técnicas que fueron utilizadas por los estadounidenses en Vietnam y luego fueron traspasadas a los militares de todo el cono sur de América. El entrenamiento de torturadores se llevó a cabo a partir de manuales que guían su formación. El Manual Kubark, creado en 1963 y utilizado para la formación de estudiantes en la Escuela de las América, es quizás el caso más ejemplar en este sentido, pues se trata de un texto fundacional del género. A partir de dicho texto se elabora luego, en 1983, otro documento llamado "Human Resource Exploitation Manual" (manual de explotación del recuso humano).

Detrás de la confección de estos manuales de tortura hay un saber de orden científico. Al inicio mismo del Manual Kubark se señala que "está basado en gran parte sobre los resultados publicados de investigaciones profundas, incluyendo consultas científicas a especialistas en asuntos relacionados directamente con el tema" (1963: 1). Insiste luego el manual con que en lo referente a la interrogación, "la principal fuente de ayuda hoy en día son los descubrimientos científicos" (1963: 2), aclarando de qué forma los psicólogos de entonces han llevado a cabo investigaciones en una serie de temas profundamente relacionados con el asunto de la interrogación, como son los efectos de la debilidad y la aislación, el polígrafo, las reacciones al miedo y al dolor, hipnosis y sugestionabilidad, narcosis, etc. "Este trabajo es de una importancia y relevancia tal que ya no es posible discutir la interrogación significativamente sin referirse a la investigación psicológica que ha tenido lugar en la década pasada" (1963: 2).

El saber del cuerpo, entonces, adquiere un lugar central en la tortura. Este lugar no solo se evidencia en el hecho de que se requiera dicho saber para hacer doler más profunda y eficientemente, sino que también se necesita para lograr que el cuerpo resista, sobreviva. La tortura no busca la muerte de la víctima: habitualmente ello ocurre por accidente. En este contexto es que se entiende la presencia de médicos y clínicas clandestinas. Como han escrito Trejos y González, "De variadas maneras pueden los médicos participar en estos momentos de aberración. El primero y más peligroso puesto que traiciona su misión sagrada, es a través de su ciencia y tecnología" (1990: 202). Estos autores 
hacen un listado de la acción concreta de los médicos. Allí se mencionan los actos de efectuar tortura directa, pero además otros modos de participación como el evaluar la capacidad de la víctima para soportar la tortura (examen de ingreso); supervisar la tortura misma y actuando médicamente si se producen complicaciones; asesorar, es decir, poner sus conocimientos técnicos al servicio de la tortura; otorgar certificados dolosos, exámenes e informes periciales que busquen ocultar lo sucedido; atender a las víctimas sin denunciar, ni renunciar (Cf.:1990: 209).

\section{Cuerpo traidor: la víctima}

Todo lo que el torturado aprende se aplica sobre un sujeto, sobre un sujeto calificado habitualmente de víctima. Si no hay víctima, no hay tortura. La víctima es quien la padece. No hay una denominación más adecuada para referirse al sujeto que es víctima de tortura que la de "paciente", pues la tortura es algo que le ocurre a alguien en contra de su voluntad. No hay consentimiento alguno de quien está completamente indefenso, sin ninguna posibilidad de oponerse, de protegerse. Dice Hernán Valdés: "Nos sentimos como conejos de jaula: nuestros amos pueden venir en el momento que quieran para escoger al que quieran y hacer con él lo que se les ocurra" (1978: 129-30).

Para las víctimas el cuerpo es omnipresente: ocupa un lugar central en los testimonios. Los sobrevivientes no ahorran en descripciones sobre las funciones más básicas -dormir, comer y defecar-, se alargan en descripciones de sus estado físico - desde las heridas hasta los olores. Tal vez hay algo de cierto en eso que decía Hannah Arendt respecto de que el proceso de transformación de un ser humano en superfluo pasa por su reducción a mera zoé, a simple vida orgánica. Para lograrlo se deben erradicar la pluralidad y la diferencia que existen entre los seres humanos, reduciéndolos a lo mínimo que todos tienen en común, a una igualdad originaria (Arendt, 1993; Agamben, 1995, 2005 y 2007; Reyes Mate, 2003): la vida orgánica, la funcionalidad corporal. Todo en la víctima, en tanto víctima, es cuerpo.

Dice Amery que "sólo en la tortura el hombre se transforma totalmente en carne... El torturado que aúlla de dolor es sólo cuerpo y nada más" (2001:98). Hernán Valdés adhiere a esta idea cuando escribe: "Siento pena de mi cuerpo. Este cuerpo va a ser torturado, es idiota. Y sin embargo es así, no existe ningún recurso racional para evitarlo. Entiendo la necesidad de este capuchón: no seré una persona, no tendré expresiones. Seré sólo un cuerpo, un bulto, se entenderán sólo con él” (1978:161). Más adelante refuerza diciendo: 
"Realmente soy -mi cuerpo es- por un simplísimo sistema de reflejos condicionados insultos-castigo, todo lo que ellos gritan" (1978: 173).

El cuerpo es para el torturado el dolor, la encarnación del dolor o como dice Le Bretón, “...el hombre torturado vive su cuerpo como la forma permanente del tormento" (1999: 249). El verdugo se encarniza contra el cuerpo y la única salvación parece ser el separarse de él, escindirse, huir del cuerpo, dejarlo, abandonarlo. En algún pasaje del relato que hace Sergio Vuskovic sobre su tortura en la Esmeralda escribe: "Tengo que tener confianza en mi cuerpo, que él continuará solo, como las otras veces, llevando adelante sus funciones. Por ahora te dejo aparcado aquí, en el mástil. En cualquier emergencia retornaré a ti. El cuerpo aprende a cuidarse a sí mismo cuando se le abandona" (16).

El cuerpo del torturado se ha transformado en su enemigo en tanto que sus "componentes físicos y sensoriales (...) se vuelven en contra de él, ofreciendo al torturador otros tantos puntos vulnerables donde administrar el tormento" (Le Breton, 1999: 249). El cuerpo le provee al verdugo de la puerta de entrada, es el puente, el doloroso camino hacia la destrucción de toda resistencia. El cuerpo traiciona a la víctima en tanto la hace vulnerable. Por eso, finalmente, es necesario huir de él, abandonarlo: él es el traidor. El naufragio, el quiebre corporal puede llevar al colapso del sujeto. "El quiebre es absoluto: físico, en tanto el cuerpo se va dañando por la aplicación constante de diversas técnicas de tortura, la falta de alimento, la insalubridad, las enfermedades no atendidas, la suciedad; subjetivo, por la humillación, el maltrato, la soledad, la indefensión, el profundo dolor" (Pérez, 2009: 113).

Hay en la literatura una distinción acríticamente aceptada entre tortura física y tortura psicológica. Todo tipo de golpes y ultrajes mecánicos, concretos, se alinean normalmente en el primer grupo, mientas que en el segundo se enumeran las amenazas, las drogas, las simulaciones (fusilamiento, violación, corriente, etc.), la vista de atrocidades, etc. Dos parecen ser los criterios entremezclados en esta distinción. Por un lado, se basaría en si existe o no contacto directo con el cuerpo de la víctima al aplicarla, por otro, ella tendría su razón en el lugar en que radicaría el efecto de la tortura: el cuerpo o la psiquis.

Si adherimos estrictamente al primer criterio, cierta técnicas de tortura pasan de ser consideradas habitualmente como psicológicas al ámbito de las torturas físicas. Evidentemente para introducir drogas, por ejemplo, se requiere de contacto, para que alguien mire atrocidades también se necesita forzar el 
cuerpo. Del mismo modo, para simular un fusilamiento se requiere manipular el cuerpo. Pronto se hace evidente que en este sentido todas la torturas son físicas: todas requieren un manipulación, un control concreto y directo sobre el cuerpo del detenido. Utilizando rígidamente el segundo criterio, la consecuencia no es diferente. El efecto de la tortura es siempre físico, así como también es siempre psicológico. ¿Qué dolor infligido con saña y alevosía sobre un cuerpo no tiene repercusiones en la psiquis? Pérez lo ha escrito sin titubear: "todo sufrimiento físico implica un desarreglo del equilibrio psíquico, de tal manera que no es posible pensar un padecimiento corporal sin la perturbación del psiquismo que conlleva. Cuando una agresión física violenta al cuerpo, se genera un quiebre que desestabiliza el funcionamiento del aparato psíquico" (2009: 105-6).

Por el otro lado, todo dolor psíquico es también físico. Así como el que es golpeado o emparrillado junto con dolerse sufre humillación, pena, frustración, etc., aquel que es aislado-incomunicado se duele corporalmente, experimenta alteraciones sensoriales, motoras, hormonales, etc. Cuenta Nubia Becker en su testimonio: "Sufríamos males reales e imaginarios que a veces nos producían disturbios hormonales y dolores imprecisos y, de repente, nos enmudecíamos por días" (1987: 93). El problema con la distinción entre torturas físicas y psicológicas es que asume una distancia entre cuerpo y psiquis difícil de sostener. La tortura siempre se ejerce sobre los cuerpos y sus efectos nunca dejan de ser tanto corporales como psíquicos. De allí también que la distinción entre dolor y sufrimiento, tan habitual en la literatura, sea difícil de sostener.

La verificación de dolores o sufrimientos está presente en todas las definiciones de tortura. No hay tortura sin dolor y sufrimiento. Ahora bien, ¿qué se califica como "dolor" o "sufrimiento"? ¿Son acaso dos cosas diferentes? ¿Es posible separarlas? En principio podría sostenerse que el dolor alude a una sensación física, sensorial, mientras que el sufrimiento se refiere a un asunto de orden afectivo. El dolor, en el caso de la tortura, sería, por lo tanto, la experiencia sensorial que se desencadena en un sujeto al recibir un castigo material. El sufrimiento, por su parte, se referiría a aquellas afecciones negativas - pena, tristeza, rabia, impotencia, humillación, etc.que se desencadenan en un sujeto al ser objeto de torturas. Esta parece ser la concepción que está detrás de las definiciones habituales de tortura, de allí la necesidad de nombrar, por un lado, los dolores, y, por otro, los sentimientos. Al hacerlo se está suponiendo que existe la posibilidad de que dolor y sufrimiento puedan darse independientemente: dolor sin sufrimiento y sufrimiento sin dolor. 
Le Breton ha señalado, con razón, que simplemente “... no hay dolor sin sufrimiento, es decir, sin significado afectivo que traduzca el desplazamiento de un fenómeno fisiológico al centro de la conciencia moral del individuo" (1999: 12). El dolor no es solo un fenómeno fisiológico, así como el sufrimiento no es tampoco uno solamente afectivo. Así como uno se duele afectivamente, uno sufre fisiológicamente. El dolor se experimenta como una sensación desagradable, incómoda, molesta, que interrumpe la normalidad. La vivencia dolorosa lleva aparejado un contexto emocional en el que se aparecen simultáneamente sentimientos de sufrimiento, de tensión y de ansiedad, entre otros.

En las definiciones de tortura, por lo tanto, es un error hablar de dolores "o" sufrimientos graves como elementos esenciales, usando una disyunción, pues no es posible que se dé uno sin el otro. Alberto Gamboa, hablando del miedo en su testimonio, tema que parece haberle preocupado como objeto de reflexión, atiende a cómo dicha afección se vincula con el cuerpo: con las piernas primero, con el estómago, la boca, la nuca después (2010: 26-27). El dolor de la tortura es de aquel tipo que Le Bretón ha llamado "dolor total". Aunque el autor lo refiere para el caso de enfermos terminales, es análogo al dolor presente en la tortura, por ser el dolor más grave. "El dolor total señala el momento en que el individuo ya no está unido al mundo más que por la irrupción de su dolor; sus sensaciones o sentimientos están inmersos en un sufrir que lo envuelve por completo" (2010:34).

El dolor total está asociado a la angustia de la muerte inminente. Es “...un dolor absoluto que aniquila al sujeto y sólo le deja una consciencia residual. La vida ha dejado de tener el menor interés; acurrucado en su infierno, el individuo desea morir lo antes posible..."(Le Breton, 1999: 35). En el testimonio de Luz Arce se lee: "Me torturaron una y otra vez, me bajaban y me volvían a subir, me cargaban como a un bulto, varias veces pensé que con algo de suerte me quebraría la columna cuando la corriente curvaba mi cuerpo como un arco. Tenía la esperanza de que las fallas cardíacas que impidieron que continuara con mi carrera deportiva se expresaran y que muriera...” (1993: 58). En el testimonio de Nubia Becker se lee, en un sentido análogo: “... allí, en el centro mismo del infierno, donde todo se vuelve en contra, y donde los amores y los recuerdos tan pronto son motivo de heroísmo como de debilidad, porque juegan en el límite de la resistencia humana y uno no quiere otra cosa que morir, para borrarse y dejar de sufrir y de temer" (1987: 16). 


\section{Marcas en el cuerpo: el daño}

Son muchos los daños que provoca la tortura. Se puede hablar aquí, sin duda, de la multidimensionalidad del daño. María José López, a propósito de la "desaparición forzada de personas" diferencia entre distintos tipos de daño: "un daño hacia la víctima, hacia sus familiares, hacia el sector social que representa..." (2015: 82). Daño individual, daño familiar, daño social: la comunidad. Como escribe Octavio Márquez, "La tortura como es obvio deja efectos, secuelas y complicaciones en las personas que la sufrieron, así como también en el nivel familiar y de la comunidad" (1999: 101).

En el plano individual, todo remite, finalmente, a una operación corporal que podría denominarse "borradura radical". Es lo que Valentina Bulo califica de "Tabula Rasa de los cuerpos" (2013). Dice esta autora que “... es en la tortura que el cuerpo queda convertido en una tabla rasa, una verdadera página en blanco sobre la cual se pueda escribir el diseño desde cero..." (2013: 209). Una tortura exitosa, lograda, una que alcanza el nivel total de blanqueo genera lo que se conoce como los "quebrados". "Al abrir dentro del cuerpo la brecha permanente del horror provoca la implosión del sentimiento de identidad, la fractura de la personalidad que conduce a veces al torturador al éxito: denuncias, renunciamiento, traición, vergüenza, locura" (Le Breton, 1999: 251-252). Se habla aquí acertadamente de una "demolición" (Perez, 2009: 113). Vaciado, ahuecado mediante el dolor, el torturado se transforma en un muñeco de ventrílocuo, una marioneta, un títere que se vuelve contra todo y todos, incluso contra sí mismo. En Chile el caso de Marcia Merino podría ser un ejemplo paradigmático de este fenómeno:

Pienso que cuando "me quiebran", me convierto en algo que solo puede sentir: miedo, dolor, asco. No quedaba ningún resquicio de racionalidad que me permitiera manejar situaciones o plantearme manejarlas. Ni siquiera tenía capacidad crítica para analizar la manipulación que la DINA estaba haciendo conmigo (1993: 53).

Según explica Le Bretón, las únicas alternativas que se presentan en esta situación de quiebre y demolición completa son la locura o la muerte (Cf.: 251). "Yo no quería vivir, quería morir. No sé por qué no me dejaron morir. Quería terminar, no quería nada más. Ni siquiera sé si en esos momentos tenía sentimientos" (Merino, 1993: 55). Marcia Merino intenta suicidarse sin éxi- 
otros lo logran. Hannah Arendt hace ver sobre este punto "que la muerte es un mal limitado" (1998: 538) si se la compara con otros males, con otro tipo de daños que resultan inconmensurables e incluso inimaginables para un sujeto normal. Algo semejante se puede decir del mal asociado a la tortura: se trata de un mal tan extremo que para muchos es preferible la muerte.

La tortura no termina con la tortura o, dicho de otra forma, la tortura es permanente: queda para siempre adherida al cuerpo. Herida, cicatriz, huella... Usando las palabras de Le Breton, "La serie de heridas siguen horadando la carne acompañadas por otros sufrimientos: depresión, úlceras gástricas, dolores de cabeza, problemas dermatológicos, respiratorios, insomnios, etc." (1999: 252). Estrés postraumático. Paz Rojas hace ver con el caso de la tortura aparece lo que la psiquiatría había descrito hace siglos como una "reacción exógena aguda”, en tanto que viene desde afuera. Esta reacción es descrita por la autora con la enumeración de una serie de trastornos a nivel de la conciencia, trastornos miméticos, trastornos de la percepción así como también trastornos del pensamiento y de la imaginación (Cf., 2004: 167-198).

La recuperación completa no parece posible: nunca nada vuelve a ser lo mismo. La frase más repetida en la intimidad de la consulta es, según comenta Paz Rojas, "nunca más volví a ser el mismo" (2004: 172). La tortura, de acuerdo con los testimonios, te cambia para siempre. Es irreversible. Según ha escrito Tomás Moulian, el torturado “... porta para siempre la marca (...). Sobrevivió a un infierno y esa huella lo acompaña hasta el fin” (2004: 54). Hablando puntualmente del caso de Agüero, Paz Rojas dice que "El temor y la angustia, que aparecieron en esos primeros momentos, persistieron a través de los años y no solo durante los 17 años que duró la dictadura sino, en muchos casos, hasta la actualidad" (2004: 168).

El daño provocado al torturar a un individuo es inconmensurable e interminable y, como se decía, se extiende a la familia y a la comunidad. El cuerpo familiar se destroza. No es ninguna excepción el caso de familias desgajadas por la experiencia de la prisión y la tortura. Cuerpos que ya no pueden con la intimidad ni con la cercanía, que no soportan ni siquiera el tocar a otro y menos intimar con él. Las parejas se separan, en algunos casos, otras se forman con el tiempo. Los hijos se resienten. Se ha hablado del "daño transgeneracional de segunda generación" para referirse a la marca definitiva sobre los descendientes de quienes fueron torturados.

El daño de la tortura se extienden más allá del núcleo familiar hacia la comunidad, hacia todo el país. La tortura, al parecer, siempre fue y es un 
medio para un fin. Históricamente la finalidad fue el castigo, la confesión, la información. En el contexto contemporáneo es la última finalidad la que ha primado. El asunto no se zanja, sin embargo, constatando que se tortura en busca de información. La verdad es que la tortura está atravesada por muchas otras finalidades además de esta. Ella tiene finalidades que trascienden la destrucción del sujeto torturado. Una de ellas es la de esparcir el terror. Pilar Calveiro ha hecho ver que "El tormento físico directo e ilimitado (...) es lo que permite diseminar el terror dentro y fuera del campo" (2008: 79). En este sentido es que López y Otero han hablado de una "pedagogía del terror" (1989: 77). En este punto es reveladora la metáfora que usa Quijada al final de su testimonio, cuando se refiere a la "extensión del campo": al salir de la prisión nunca siente que fue liberado realmente, pues su ciudad, su país, se le presentan como un gran campo de prisioneros. Uno tan eficiente que lo mantiene atrapado al interior de su casa, sin poder salir: todavía encerrado.

La tortura, en algunos casos, pretende, además, romper, quebrar las redes sociales. En términos de Valentina Bulo, “... la tortura es el ejercicio de desescribir un nosotros, de desgarrarlo, quebrar el cuerpo general, cuerpo común"(2013: 209). La desconfianza, la traición, la sospecha de delación/ colaboración van carcomiendo el tejido social hasta descomponerlo. El cuerpo de Chile, del Chile que fuimos, se desmoronó hasta desaparecer. El artefacto que hizo posible esta destrucción fue la tortura. Lo que se destruyó fueron los vínculos existentes y, a la vez, la posibilidad de construcción de relaciones. Un buen ejemplo de lo que se viene diciendo es el relato de Nubia Becker de su encuentro con Matías, un ex compañero de prisión.

Yo, también me alegré mucho de verlo, pero por una cuestión de precaución no le dije donde vivía. Fue una pena, pero lo hice y aún me pesa mucho. Fue una especie de alerta por su parentesco con un colaborador de la DINA, lo que me señaló el peligro y, a pesar de que su gesto eran tan sincero tan abierto, equivocada o no, me dije a mí misma que no podía darme el lujo de mantener esos lazos porque esa experiencia humana, ese cálido afecto surgido en el horror, se chocaba con las barreras reales o imaginarias que yo levantaba (44).

Esparcir el terror en la sociedad, educar o más bien controlar a la población, demoler el tejido social son finalidades de la tortura que afectan directamente al cuerpo social. La tortura extiende su efecto, su daño se expande sobre la comunidad, sobre el país. 


\section{Recapitulación}

Para terminar, tan solo una recapitulación. Se decía, al comenzar, que el objetivo era hacer una aproximación temática: abordar la tortura desde la perspectiva del cuerpo. Como se ha podido observar, el cuerpo está presente por todas partes cuando hablamos de tortura, todo en ella es cuerpo. El cuerpo colma, inunda el fenómeno. Es así como se ha visto que el cuerpo se vuelve un arma en el caso del verdugo, que es el traidor para la víctima, que la intervención del cuerpo en la tortura es tecnológica y científica, que el cuerpo de los torturados es esencialmente adolorido, está lleno de heridas que se trasfieren a sus familias y a su comunidad. Se trata tan solo de algunas líneas de lectura que muestran nítidamente que en la tortura "todo es cuerpo".

\section{Referencias bibliográficas}

Agamben Giorgio (1995), Homo sacer I. El poder soberano y la nuda vida, Pretextos, Valencia.

(2007), Estado de excepción, Adriana Hidalgo Editora,

Buenos Aires.

(2005), Lo que queda de Auschwitz. El archivo y el testigo. Homo sacer III, Pre- textos, Valencia.

A méry Jean (2001), Más allá de la culpa y la expiación, Valencia, Pre Textos, 2001 (Jenseits von Schuld und Sühne, Szczeny Verlag, München, 1965).

Arce Luz (1993), El Infierno, Ed. Océano [Planeta], Santiago.

Arendt Hannah (1984), La vida del espiritu. El pensar, la voluntad y el juicio en la filosofía y en la política, R. Montoro y F. Vallespín (trad.), Centro de Estudios Constitucionales Madrid.

(1998), Los origenes del totalitarismo, Guillermo Solana

(trad.), Taurus, Madrid.(The Origins of Totalitarianism (1994), Hartcourt,New York). 
Aristóteles (1995), Metafísica, Gredos, Madrid.

Bulo Valentina (2013), "Tabula rasa de los cuerpos”, La Cañada. Revista del pensamiento filosófico chileno, No 4, pp. 206-214.

Calveiro Pilar (2008), Poder y desaparición. Los campos de concentración en Argentina, Colihue, Buenos Aires.

CIA (1963), Kubark, comuner intelligence Interrogation.

CODEPU (1985), Informe de Denuncia CODEPU. La tortura: una necesidad de régimen. ( $O$ de cómo la dictadura necesita torturadores).

Egaña Rafael (2005), Narraciones de la tortura. Su representación en tres textos dramáticos, tesis para optar al título de Antropología Social, U. de Chile

Fuentes K., \& Correa J. (2010), Los cuerpos castigados del cuartel Terranova, Chile (1974-1978)", Actual Marc, Intervenciones, No 9, Cuerpos contemporáneos: nuevas prácticas, antiguos retos, otraspasiones, Dom, Santiago, pp. 77-92.

Gamboa Alberto (2010), Viaje al infierno, Editorial Forja, Santiago (Publicado originalmente por Editorial Araucaria, Santiago, 1984).

Garretón Roberto (2004), “Qué es ser "torturador"?", De la tortura no se habla, Agüero Versus Meneses, Patricia Verdugo (ed.), Catalonia, Santiago, pp. 141-159.

Guerrero Manuel (1999), La tortura: poder y saber resistencial, Universidad Arcis, Santiago.

Le Breton David (1999), Antropología del dolor, Daniel Alcoba (trad.), Seix Barral, Barcelona.

López Ricardo y Otero Edison (1989), Pedagogía del terror: un ensayo sobre la tortura, Atena, Santiago.

López María José (2015), “El desaparecido como sujeto político: una lectura desde Arendt”, Franciscanum 164, Vol. LVII, pp. 67-95. 
Madariaga C. (1989), "Tortura, Persona y Sociedad”, Revista Reflexión No104.

Maier Andreas (2011), “Torture”, Humiliation, Degradation, Debumanization: Human Dignity Violated, Paulus Kaufmann, Hannes Kuch, Christian Neuhäuser, Elaine Webster (eds.), pp. 101-118.

Marchant Patricio (2000), “Desolación. Cuestión del nombre de Salvador Allende (1989-90)”, Escritura y temblor, Cuarto Propio, Santiago, pp. 213-234.

Márquez Mendoza Octavio (1999), “Tortura, dolor psíquico y salud mental”, CODHEM, Revista Derechos Humanos. Órgano Informativo de la Comisión de Derechos Humanos del Estado de México, No 37 (Mayo -Junio).

Marrades Julina (2005), “La vida robada. Sobre la dialéctica de dolor y poder en la tortura”, Pasajes No 17, pp. 28-39

Merino Marcia (1993), Mi verdad: más allá del horror, yo acuso, ATGSA, Santiago.

Moya Laura (2005), Tortura en poblaciones del gran Santiago (1973-1990), Corporación José Domingo Cañas, Santiago.

Moulian Tomás (2004), "El gesto de Agüero y la amnesia”, De la tortura no se habla, Patricia Verdugo (comp.), Catalonia, Santiago, pp. 45-60.

Pereyra Daniel (2004), “Argentina: militares torturadores”, Mientras Tanto, No 90 (Primavera), pp. 79-96

Pérez Vilar Natalia (2009), La tortura como inscripción del dolor en el cuerpo, TRAMAS 32 , UAM-X, México, pp. 99-120.

Reszcynski Katia, Paz Rojas y Patricia Barceló (1991), Tortura y resistencia en

Chile: estudio médico-politico, Editorial Emisión,Santiago (Escrita en 1979).

Reyes Matte Manuel (2003), Memoria de Auschwitz. Actualidad moral y politica, Editorial Trotta, Madrid.

Rojas, Carmen [Becker Nubia] (1987), Recuerdos de una Mirista, Ediciones del Taller, Santiago. (Publicado nuevamente bajo el nombre Una mujer en 
Rojas B, Paz (2004), “Torturas. Romper el silencio”, De la tortura no se habla, Patricia Verdugo (ed.), Catalonia, Santiago, pp.161-180.

Sánchez, Domingo (1990), "La tortura: un enfoque social", Tortura: Aspectos médicos, psicológicos y sociales. prevención y tratamiento, E. DITT-CODEPU, CODEPU, Santiago.

Soto, H. (1999) Voces de Muerte Iy II, Editorial LOM, Santiago.

Sussman, David (2005), "What's Wrong with Torture?", Philosophy and Public Affairs, $\mathrm{N}$ o 33, pp. 1-33.

Trejos y González (1990 [1986]), "Participación de Médicos en Torturas. Terceras Jornadas de Ética Médica”, Comisión Nacional contra la Tortura, Memoria (1983-1990), LOM, Santiago, pp.191-215.

Tricot, Tito (1990), "La Tortura: Agencia Primaria del Terror", Tortura: Aspectos médicos, psicológicos y sociales. prevención y tratamiento. E. DITTCODEPU, (ed.), CODEPU, Santiago. http://www.blest.eu/biblio/seminario/ cap1.html

Valdés, Hernán (1978), Tejas verdes : Diario de un Campo de Concentración en Chile, Ediciones LAIA, Barcelona (primera edición en Editorial Ariel, Barcelona 1974).

Vásquez, Ana, Rojas, Paz y Reszcynski, Katia (1994), Efectos de la prisión y la tortura aplicada por el sistema represivo chileno en el prisionero politico.

Verdugo, Patricia (ed.) (2004), De la tortura no se habla. Agüero versus Menesses, Catalonia, Santiago.

Vidal, Hernán (2000), Chile: poética de la tortura politica, Mosquito Editores, Santiago.

Westin, C. (1994), Tortura y Existencia, Ediciones Universidad Academia de Humanismo Cristiano, Santiago. 